\title{
Contrast-induced Acute Kidney Injury
}

\author{
Pratheema Ramachandran ${ }^{1}$, Devachandran Jayakumar ${ }^{2}$
}

\begin{abstract}
Contrast-induced acute kidney injury (CI-AKI) is the third common cause of kidney injury in hospitalized patients. It describes a wide spectrum of kidney injury from mild and reversible to permanent and irreversible. The mechanism of contrast-induced AKI and strategies to prevent it are not clearly understood. This review discusses the various contrast agents, pathophysiology of $\mathrm{Cl}-\mathrm{AKI}$ and different preventive strategies.

Keywords: Acute kidney injury, Contrast-induced acute kidney injury, Nephrotoxicity.

Indian Journal of Critical Care Medicine (2020): 10.5005/jp-journals-10071-23379
\end{abstract}

\section{INTRODUCTION}

Advances in radiodiagnosis and angiography have led to improved clinical diagnosis and safe patient management in recent years. Most modern radiological techniques involve the administration of iodinated radiocontrast material to delineate vascular structures and hollow viscus for accurate diagnosis, and precise interventions. One of the major adverse effects of this iodinated intravascular contrast is contrast-induced acute kidney injury (Cl-AKI), formerly known as contrast-induced nephropathy (CIN). Contrast-induced acute kidney injury is the third most common cause for acute kidney injury (AKI) in hospitalized patients. ${ }^{1}$ It is usually mild and reversible, but in some patients, it can cause irreversible kidney injury requiring renal replacement therapy. Since $\mathrm{Cl}-\mathrm{AKI}$ is predominantly related to iodinated contrast, non-iodinated contrast-related renal insufficiency will not be discussed in this review.

\section{Definition And InCIDENCE}

Contrast-induced acute kidney injury is suspected when there is a decline in renal function following recent intravascular administration of contrast media for imaging or interventional purposes.

There is no universally accepted definition for Cl-AKI. Kidney Disease Improving Global Outcomes guidelines published in 2012 recommended the use of AKI definition for $\mathrm{Cl}-\mathrm{AKI}$, which is ${ }^{2}$

- Absolute increase in creatinine of $\geq 0.3 \mathrm{mg} / \mathrm{dL}$ within 48 hours of administration of intravascular contrast material or

- Increase in creatinine of at least 50\% above baseline within 7 days of administration of intravascular contrast material or

- A urinary volume of less than $0.5 \mathrm{~mL} / \mathrm{kg}$ of body weight/hour that persists for at least 6 hours after exposure

A diagnosis of $\mathrm{Cl}-\mathrm{AKI}$ should be made only after excluding other potential causes of AKI (hemodynamic shock, rhabdomyolysis, use of nephrotoxic drugs and urinary tract obstruction).

The incidence of $\mathrm{Cl}-\mathrm{AKI}$ depends on patient factors, type of procedure performed, route of contrast administered and the definition applied. ${ }^{2}$ Coronary angiography and angioplasty are more likely to cause $\mathrm{Cl}-\mathrm{AKI}$ than other contrast studies with an incidence estimated between $3 \%$ and $13 \% .{ }^{2}$ In patients with normal renal function, the incidence of $\mathrm{Cl}-\mathrm{AKI}$ is estimated to be between $1 \%$ and $2 \% .^{3}$ In preexisting renal dysfunction with or without other risk factors like advanced age, diabetes, congestive heart failure and
${ }^{1,2}$ Department of Critical Care Medicine, Apollo Hospitals, Chennai, Tamil Nadu, India

Corresponding Author: Pratheema Ramachandran, Department of Critical Care Medicine, Apollo Hospitals, Chennai, Tamil Nadu, India, Phone: +91 9843385979, e-mail: pratheema.ram@gmail.com

How to cite this article: Ramachandran P, Jayakumar D. Contrast-induced Acute Kidney Injury. Indian J Crit Care Med 2020;24(Suppl 3):S122-S125. Source of support: Nil

Conflict of interest: None

administration of other nephrotoxic drugs its incidence can be as high as $25 \% .{ }^{4}$ It affects $11 \%$ of hospitalized patients and is the third most common cause for AKI in hospitalized patients. ${ }^{1}$

Several small studies have shown an association between $\mathrm{Cl}$-AKI and mortality. ${ }^{1,5}$ Majority of these studies included patients undergoing coronary intervention, which makes it impossible to generalize these findings to other patient groups. Moreover, patients with chronic kidney disease (CKD) are increasingly less likely to undergo procedures or imaging that involves the administration of radiocontrast material. Therefore, it is impossible to know whether contrast is truly causative of AKI. Contrast-induced acute kidney injury is likely to prolong hospital stay, but its attributable mortality is still largely unknown. ${ }^{6}$

\section{Types of Contrast Media and Pathophysiology of CI-AKI}

Based on their osmolality relative to serum, iodinated contrast media are classified into high, low, and iso-osmolal materials. Highosmolal materials, also called first-generation materials or ionic contrast, typically have 5-8 times the osmolality of body fluids (1400-2200 mOsm/kg water). High incidence of adverse reactions secondary to the osmotic effect led to high-osmolal agents falling out of favor. They are rarely used in clinical practice nowadays. ${ }^{7}$

Low-osmolal agents (second-generation agents or nonionic contrast) with an osmolality between 600 and $800 \mathrm{mOsm} / \mathrm{kg}$ water cause fewer adverse reactions and are well tolerated. Nevertheless, they are still hypertonic and have the potential to cause AKI. They are less expensive and are the most commonly used contrast agents in clinical practice. ${ }^{7}$

Iso-osmolal contrast agents or third-generation contrast agents have similar osmolality to that of serum. They are well tolerated but

(c) The Author(s). 2020 Open Access This article is distributed under the terms of the Creative Commons Attribution 4.0 International License (https://creativecommons. org/licenses/by-nc/4.0/), which permits unrestricted use, distribution, and non-commercial reproduction in any medium, provided you give appropriate credit to the original author(s) and the source, provide a link to the Creative Commons license, and indicate if changes were made. The Creative Commons Public Domain Dedication waiver (http://creativecommons.org/publicdomain/zero/1.0/) applies to the data made available in this article, unless otherwise stated. 
have high viscosity and are very expensive. Considering their high cost and the equal to marginally reduced risk of $\mathrm{Cl}-\mathrm{AKI}$ compared to low-osmolal agents, the use of iso-osmolal agents is restricted to patients at high risk of developing $\mathrm{Cl}^{-\mathrm{AKI}}{ }^{7}$

\section{Pathophysiology}

Contrast media can cause kidney injury by direct or indirect mechanisms. $^{8}$

\section{Indirect Mechanisms}

Contrast agents cause fluctuations in the blood flow both regionally and globally. The outer medulla with its physiologically low oxygen saturation along with high metabolic demand makes it vulnerable for injury when there is associated reduction in blood flow by contrast media. ${ }^{6,7}$ The local reduction of blood flow is mediated by vasoactive substances like increased endothelin, renin-angiotensin, and decreased prostaglandin and nitric oxide. With a half-life of around 2 hours, contrast gradually gets excreted through the kidneys. By 24 hours, they are completely excreted from the body. During excretion, they pass through the tubules causing an increased osmotic force which increases sodium and water excretion. This in turn, increases intratubular pressure, thereby reducing the glomerular filtration rate (GFR). Contrast agents also increase blood viscosity, decrease microcirculation, affect the plasticity of erythrocytes and cause microvascular thrombosis. ${ }^{7}$

\section{Direct Mechanisms}

lodinated contrast media are toxic to the epithelial cells of the tubules causing necrosis and apoptosis. There is redistribution of basolateral $\mathrm{Na}^{+} / \mathrm{K}^{+}$ATPase to luminal surface causing increased $\mathrm{Na}$ delivery to the distal tubules. The damaged epithelial cells detach and clog the tubular lumen, increasing intratubular pressure, thereby reducing the GFR further. ${ }^{8}$

\section{Risk Factors for Cl-AKI}

- Contrast-related factors

- Patient-related factors

\section{Contrast-related Factors}

Osmolality, viscosity, volume, and route of contrast administered (Table 1) are major determinants of $\mathrm{Cl}-\mathrm{AKI} .{ }^{6,7}$

Clearly, the risk of developing $\mathrm{Cl}-\mathrm{AKI}$ is much higher with firstgeneration high-osmolal agents. It is widely accepted that high osmolality is associated with AKI, but there is some suggestion

Table 1: Contrast media $^{7}$

\begin{tabular}{llll}
\hline Class & & Agents & Osmolality \\
\hline High osmolar & $\begin{array}{l}\text { lonic } \\
\text { monomers }\end{array}$ & lothalamate & $1,400-2,000$ \\
& & $\begin{array}{l}\text { Diatrizoate } \\
\text { Metrizoate }\end{array}$ \\
Low osmolar & $\begin{array}{l}\text { Nonionic } \\
\text { Monomers } \\
\text { lonic dimer }\end{array}$ & $\begin{array}{l}\text { lohexol } \\
\text { loversol }\end{array}$ & lopamidol \\
& & $\begin{array}{l}\text { lopromide } \\
\text { loglaxate }\end{array}$ & \\
& & lodixanol & 300 \\
Iso-osmolar & Nonionic & lotrolan & \\
& & &
\end{tabular}

that viscosity is more important than osmolality, ${ }^{7}$ since it alters the rheologic property of the fluids. Studies comparing lowosmolal and iso-osmolal agents showed no difference in the risk of developing AKI, supporting the viscosity theory.

Other important factors are the volume of contrast administered, route of administration ${ }^{9}$ and the type of procedure performed. Higher volumes tend to cause more osmotic effect, reduce GFR, stay in the tubules for longer and cause direct injury to the tubular cells. ${ }^{8}$ Incidence of $\mathrm{Cl}$-AKI is more after intra-arterial administration of contrast than intravenous administration. Angiography (arterial or venous) certainly carries a much higher risk compared with contrast-enhanced computed tomography. ${ }^{7}$

\section{Patient-related Factors}

Incidence of $\mathrm{Cl}-\mathrm{AKI}$ increases with age, preexisting renal disease, diabetic nephropathy, simultaneous use of nephrotoxic drugs, dehydration, hemodynamic instability, anemia and other causes of

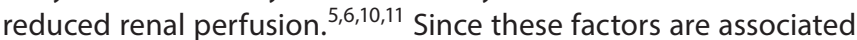
with low renal reserve, administration of contrast increases the risk of developing AKI.

Several prediction models have been proposed to identify patients at risk of developing $\mathrm{Cl}-\mathrm{AKI} .{ }^{6}$ These models have incorporated various patient, procedural, and contrast-related factors to arrive at a final score to predict the risk. ${ }^{6}$ They were constructed using large cohorts of patients undergoing coronary interventions. One such model proposed by Mehran et al. ${ }^{12}$ is given in Table 2. Although not widely used, they are quite useful in predicting $\mathrm{AKI}$ in patients undergoing coronary intervention.

\section{Recent Developments in Prediction and DiAgnosis}

Prediction and diagnosis of AKI from contrast administration involves a careful assessment of patient-related risk factors, volume of contrast used, interval between contrast administration, and the change in renal parameters. ${ }^{13}$ Changes in the fluid balance have an effect on serum creatinine which affects the diagnosis of AKI. In some studies, paradoxically, a decreasing serum creatinine was associated with increased mortality in postsurgical patients. ${ }^{6}$ This uncertainty with creatinine led to the search for biomarkers, and bedside ultrasound has been suggested to predict and diagnose $\mathrm{Cl}-\mathrm{AKI}$.

\begin{tabular}{ll} 
Table 2: Mehran et al.'s risk sore for contrast-induced nephropathy ${ }^{6,12}$ \\
\hline Parameter & Score \\
\hline Hypotension & 5 \\
Intra-aortic balloon pump & 5 \\
Congestive heart failure & 5 \\
Diabetes & 3 \\
Contrast media & 1 for each $100 \mathrm{~mL}$ \\
Age $>75$ years & 4 \\
Serum creatinine $>1.5 \mathrm{mg} / \mathrm{dL}$ & 4 \\
Anemia & 3 \\
estimated glomerular filtration rate $<60 \mathrm{~mL} /$ & 2 \\
minute/1.73 cm ${ }^{2}$ & \\
\hline Score & CIN risk (\%) \\
\hline$>6$ & 7.5 \\
$6-10$ & 14 \\
$11-16$ & 26.1 \\
$>16$ & 57.3 \\
\hline
\end{tabular}




\section{Biomarkers}

These can be used to detect AKI post-contrast exposure. Although helpful in early detection of AKI before a change in creatinine, these biomarkers are not specific for $\mathrm{Cl}$-AKI. Biomarkers like urinary neurogelatinase-associated lipoprotein ${ }^{14}$ and urinary interleukin-18 indicate renal injury within 2-4 hours of insult. Other biomarkers like fatty acid-binding protein and kidney injury molecule-1 also indicate toxic injury to the renal tubules.

\section{Renal-resistive Index ${ }^{15}$}

Assessing renal-resistive index (RRI) with bedside ultrasound to predict AKI has been studied lately. Like the biomarkers, it is not specific for $\mathrm{Cl}-\mathrm{AKI}$. The changes in renal blood flow detected by RRI help detect various renal pathologies. It has been used to assess post-renal transplant allograft function, renovascular hypertension, etc. A high RRI before administration of contrast is a good predictor of $\mathrm{Cl}-\mathrm{AKI}$.

\section{TREATMENT}

There is no specific treatment for $\mathrm{Cl}-\mathrm{AKI}$. The treatment is similar to AKI from other causes. Hence, strategies have been the suggested and followed to prevent the development of $\mathrm{Cl}-\mathrm{AKI}$.

\section{Preventive Strategies: Non- PHARMACOLOGICAL}

Identifying patients at risk and weighing the risks and benefits of administering contrast with a view to reducing the risk prevent the morbidity associated with $\mathrm{Cl}-\mathrm{AKI}$. If the risks far outweigh the benefits, it becomes important to explore alternate imaging modalities to avoid contrast exposure.

Well-established preventive strategies are as follows:

- Using the minimum volume of contrast possible without compromising the image quality. ${ }^{16}$

- Avoiding repeat exposure to contrast within 72 hours. $^{6}$

- Assessing and adequately addressing volume depletion, thereby avoiding activation of renal angiotensin mechanism which leads to vasoconstriction. Improved urine flow in the tubules prevents contrast stasis and hence reduces the direct injury risk. ${ }^{17}$

- Avoiding concurrent usage of nephrotoxic drugs. ${ }^{17}$

\section{Volume of Contrast Media}

These that can be used safely with minimal effects on kidney have been widely studied. Brown et al. $^{16}$ in their study introduced maximum acceptable contrast dose which is calculated as $5 \times$ body weight/ $88.4 \times$ serum creatinine $(\mathrm{mmol} / \mathrm{L})$. Dose exceeding this has been associated with AKI. Repeated administration within 72 hours is also associated with higher risk.

\section{Concurrent Use of Nephrotoxic Drugs}

Angiotensin-converting enzyme (ACE) inhibitors, nonsteroidal anti-inflammatory drugs (NSAIDs), cyclooxygenase-2 inhibitors, metformin and antivirals like acyclovir and foscarnet increase the risk of AKI in patients exposed to contrast materials. In practice, for elective cases, ACE inhibitors are discontinued on the day of contrast administration, but this has not been proven to be beneficial. Avoidance of NSAIDs is appropriate. Metformin is generally held a day before contrast exposure and has been shown to be beneficial.
It is not nephrotoxic, but it causes lactic acidosis if the patient were to develop AKI post-contrast. ${ }^{6}$

\section{Remote Ischemic Preconditioning}

It is believed that a transient hypoperfusion or ischemia in one organ/area of the body has protective effects in others. Intermittent inflation of an upper arm cuff arm causing ischemia reduces the risk of $\mathrm{Cl}$-AKI in high-risk patients. ${ }^{18}$ Well-validated clinical studies are needed before this becomes a regular practice.

\section{Preventive Strategies: Pharmacological}

Volume expansion with normal saline is found to be the most physiologically appropriate strategy to reduce the risk of $\mathrm{Cl}-\mathrm{AKI}$. Saline improves the urine flow hence dilutes the contrast media and reduces its concentration and osmolality. This reduces the intraluminal block and back pressure. Volume expansion also inhibits the renin-angiotensin system, thereby preventing renal vasoconstriction. .7,19,20 $^{2}$

Although observational data to support volume expansion is very strong, clinical trials have thus far failed to favor this preventive strategy. This could be due to various factors including methodological issues. The volume of intravenous saline required for prevention is still unknown and is likely to be different for different patients. Despite this lack of clarity, American College of Radiology recommends $100 \mathrm{~mL} /$ hour saline for $6-12$ hours before and 4-12 hours after any angiography. Since this is not practical for urgent procedures, intravenous fluids can be given for 1-3 hours before and 6 hours after an urgent procedure. Patients with poor left ventricular function and chronic kidney disease are at risk of overload; therefore, volume expansion needs to be done cautiously. $6,19,20$

Sodium bicarbonate $\left(\mathrm{NaHCO}_{3}\right)^{17}$ is thought to reduce free radicals and increase neutralization of active oxygen species produced by contrast in renal tubules by alkalinizing the urine. A large multicenter randomized controlled trial comparing saline and bicarbonate did not show any difference between the two interventions. Therefore, routine use of bicarbonate infusion to prevent $\mathrm{Cl}-\mathrm{AKI}$ cannot be recommended.

Antioxidants such as $\mathrm{N}$-acetyl cysteine ${ }^{17}$ are expected to be effective due to their ability to reduce/counteract the free radicals produced in the tubule. N-Acetyl cysteine is commonly used in clinical practice to reduce the risk of $\mathrm{Cl}-\mathrm{AKI}$. Although retrospective clinical data support its usage, large clinical trials have not shown any benefit thus far. Its routine use to prevent AKI is not recommended.

Theophylline ${ }^{17}$ is a nonselective adenosine receptor antagonist. Adenosine is believed to mediate vasoconstriction after contrast administration. This mechanism is found to be negated by theophylline. Although theoretical explanation holds good, studies did not show a beneficial role with the use of theophylline. Rather this drug had significant gastrointestinal and cardiovascular side effects.

Statins ${ }^{17}$ (3-hydroxy-3-methyl-glutaryl-CoA reductase inhibitors) are also known to be anti-inflammatory and have antioxidant properties. Multiple studies have evaluated the effect of short-term high-dose statins in preventing $\mathrm{Cl}-\mathrm{AKI}$. Despite the proposed benefits, they are not widely used because of differing study protocols and conflicting results of the trials.

Other drugs such as calcium channel blockers, allopurinol, fenoldopam, dopamine and prostaglandin E1 have all been studied 


\begin{tabular}{|c|c|c|}
\hline S. no. & Imaging & Indications \\
\hline \multirow[t]{3}{*}{1} & TOF MR angiography & Cerebral aneurysm stroke \\
\hline & & AV malformation \\
\hline & & $\begin{array}{l}\text { Peripheral artery disease } \\
\text { (less frequently) }\end{array}$ \\
\hline \multirow[t]{2}{*}{2} & $\begin{array}{l}\text { ECG-gated fast spin echo MR } \\
\text { angiography }\end{array}$ & Peripheral artery disease \\
\hline & & $\begin{array}{l}\text { Thoracoabdominal aortic } \\
\text { aneurysm }\end{array}$ \\
\hline \multirow[t]{3}{*}{3} & SSFP MR imaging & Myocardial viability \\
\hline & & Pericardial diseases \\
\hline & & Congenital heart diseases \\
\hline 4 & $\begin{array}{l}\text { Arterial spin labeling with/ } \\
\text { without SSFP }\end{array}$ & $\begin{array}{l}\text { SSFP native and } \\
\text { transplanted kidney } \\
\text { perfusion, evaluation of } \\
\text { organ perfusion }\end{array}$ \\
\hline 5 & Phase contrast MR imaging & $\begin{array}{l}\text { Imaging of major } \\
\text { thoracoabdominal vascu- } \\
\text { lature }\end{array}$ \\
\hline 6 & Carbon dioxide angiography & $\begin{array}{l}\text { Peripheral artery disease } \\
\text { (mostly infradiaphragmatic) }\end{array}$ \\
\hline
\end{tabular}

TOF, time-of-flight; MR, magnetic resonance, ECG, electrocardiography, SSFP, steady-state free precession; AV, arteriovenous

to prevent $\mathrm{Cl}-\mathrm{AKI}$, but the lack of evidence does not support the use of these agents in clinical practice. ${ }^{17}$

\section{Newer Methods of Non-contrast IMAGING ${ }^{21}$}

Newer imaging techniques without the need for iodinated contrast are being considered recently. These are mostly magnetic resonance-based studies. They are not widely available, and many are specialized studies which require skill and expertise (Table 3).

\section{Conclusion}

Despite the many unknowns surrounding $\mathrm{Cl}-\mathrm{AKI}$, it must be acknowledged that it is a recognized problem in patients undergoing contrast-enhanced studies and procedures. Judicious use of contrast after a careful risk assessment and application of appropriate preventive measures are likely to reduce the risk of developing $\mathrm{Cl}-\mathrm{AKI}$.

\section{References}

1. Nash K, Hafeez A, Hou S. Hospital-acquired renal insufficiency. Am J Kidney Dis 2002;39(5):930-936. DOI: 10.1053/ajkd.2002.32766.

2. Kidney International Supplements 2012;2(1):1.

3. Berns A. Nephrotoxicity of contrast media. Kidney Int 1989;36(4): 730-740. DOI: 10.1038/ki.1989.254.

4. Rudnick M, Goldfarb S, Tumlin J. Contrast-induced nephropathy: is the picture any clearer? Clin J Am Soc Nephrol 2007;3(1):261-262. DOI: 10.2215/CJN.04951107.
5. Rihal C, Textor S, Grill D, Berger $P$, Ting $H$, Best $P$, et al. Incidence and prognostic importance of acute renal failure after percutaneous coronary intervention. Circulation 2002;105(19):2259-2264. DOI: 10.1161/01.cir.0000016043.87291.33.

6. Mehran R, Dangas G, Weisbord S. Contrast-associated acute kidney injury. New England J Med 2019;380(22):2146-2155. DOI: 10.1056/ NEJMra1805256.

7. Do C. Intravenous contrast: friend or foe? a review on contrastinduced nephropathy. Adv Chronic Kidney Dis 2017;24(3):147-149. DOI: 10.1053/j.ackd.2017.03.003.

8. McCullough P. Contrast-induced acute kidney injury. J Am Coll Cardiol 2008;51(15):1419-1428. DOI: 10.1016/j.jacc.2007.12.035.

9. Heyman SN, Clark BA, Kaiser N, Spokes K, Rozen S, Brezis M, et al. Radiocontrast agents induce endothelin release in vivo and in vitro. J Am Soc Nephrol 1992;3(1):58-65.

10. Nikolsky E, Mehran R, Lasic Z, Mintz G, Lansky A, Na Y, et al. Low hematocrit predicts contrast-induced nephropathy after percutaneous coronary interventions. Kidney Int 2005;67(2):706-713. DOI: 10.1111/j.1523-1755.2005.67131.x.

11. Lang D. Radiocontrast nephropathy: a paradigm for the synergism between toxic and hypoxic insults in the kidney. Radiology 1995;195(1):82-82. DOI: 10.1148/radiology.195.1.82.

12. Mehran R, Aymong E, Nikolsky E. A simple risk score for prediction of contrast-induced nephropathy after percutaneous coronary intervention. ACC Curr J Rev 2005;14(3):41. DOI: 10.1016/ j.accreview.2005.02.034.

13. Mamoulakis C, Tsarouhas K, Fragkiadoulaki I, Heretis I, Wilks $M$, Spandidos D, et al. Contrast-induced nephropathy: basic concepts, pathophysiological implications and prevention strategies. Pharmacol Ther 2017;180:99-112. DOI: 10.1016/ j.pharmthera.2017.06.009.

14. Tong J, Li H, Zhang H, Luo Z, Huang Y, Huang J, et al. Neutrophil gelatinase-associated lipocalin in the prediction of contrast-induced nephropathy. J Cardiovasc Pharmacol 2015;66(3):239-245.

15. Hetzel G, Hetzel G, May P, Hollenbeck M, Voiculescu A, Mödder U, et al. Assessment of radiocontrast media induced renal vasoconstriction by color coded duplex sonography. Ren Fail 2001;23(1):77-83. DOI: 10.1081/jdi-100001286.

16. Brown J, Robb J, Block C, Schoolwerth A, Kaplan A, O'Connor G, et al. Does safe dosing of iodinated contrast prevent contrastinduced acute kidney injury? Circulation: Cardiovascular Interventions 2010;3(4):346-350. DOI: 10.1161/CIRCINTERVENTIONS. 109.910638 .

17. Subramaniam R, Suarez-Cuervo $C$, Wilson $R$, Turban $S$, Zhang A, Sherrod $C$, et al. Effectiveness of prevention strategies for contrastinduced nephropathy. Ann Intern Med 2016;164(6):406. DOI: 10.7326/ M15-1456.

18. Igarashi $\mathrm{G}$, lino $\mathrm{K}$, Watanabe $\mathrm{H}$, Ito $\mathrm{H}$. Remote ischemic preconditioning alleviates contrast induced acute kidney injury in patients with moderate chronic kidney disease. Circulation Journal 2013;77(12):3037-3044. DOI: 10.1253/circj.cj-13-0171.

19. Ali A, Bhan C, Malik M, Ahmad M, Sami S. The prevention and management of contrast-induced acute kidney injury: a mini-review of the literature. Cureus 2018;10(9):e3284. DOI: 10.7759/cureus. 3284.

20. Bader B, Berger E, Heede M, Silberbaur I, Duda S, Risler T, et al. What is the best hydration regimen to prevent contrast mediainduced nephrotoxicity? Clin Nephrol 2004;62(07):1-7. DOI: 10.5414/ cnp62001.

21. Ozkok S, Ozkok A. Contrast-induced acute kidney injury: a review of practical points. World J Nephrol 2017;6(3):86-99. DOI: 10.5527/wjn. v6.i3.86. 